\title{
CO2 Zero-House Design with Mobile Smart Home Technology
}

\author{
Junyon Kim \\ Flower-Landscape Dept., Korea Nazarene University, 456 Ssangyong, Cheonan, \\ Chungnam, 331-718, Korea
}

kjflower@kornu.ac.kr

\begin{abstract}
Countries in the world as well as Korea are continuing to study the structure of low energy consumption type which enables the building to be operated with a smath dmount of energy in order to reduce greenhouse gas emission. Therefore, this study condugted the eco-friendly zero-house modeling Based on mobile home network advanced from the structure of low energy consumption type. It was designed to be self-sufficient in energy by self-producing energy through new renewable energy, applying all sorts of zero-house technology, minimizing the use of energy used in the blitding, and continuing to monitor and control energy through the mobile appliance
\end{abstract}

Keywords: Zero-House, Mobile Home, Network, Eco-Friendly

\section{Introduction}

Discussion and practice of the society wise reconstruction and earth environment of sustainability are progressing at the global level. Especially, international cooperation is active such as the conclusion of international treaties including the Climatic Change Convention in order to resolve the environmental problem at the earth level. All sorts of regulatory means are being developed by setting the target amount of each country and achieving it in order to reduee the emissions of greenhouse gas such as $\mathrm{CO} 2$ and the like. Accordingly, it is becoming a national task to develop the greenhouse gas abatement technology, energy-saving technology and so on.

The amount of energy consumed by structures such as housing and building in Korea accounts for $25 \%$ of the total energy consumption. Korea aims to reduce $30 \%$ of greenhouse gas emission up to 2020 by adopting low-carbon green growth as the national long-term strategy in 2008. And seeing that Korean government is planning the national roadmap to obligate newly-built housing to secure zero-energy performance in 2025 , it is necessary to conduct a study of the environment-friendly design technique and environment-friendly technology.

Therefore, this study attempts to introduce the home network system using the mobile appliance to implement the structure in which the sum of annual energy budget equals zero $(0)$.

For this purpose, chapter 2 attempts to make a theoretical investigation of the concept, function and major technology of environment-friendly zero house, the home network and the mobile home network.

Chapter 3 discusses GT(Green IT), MEMS(Mobile Energy Management System), 3.3 Mobile Smart Home Control System to conduct a study of the zero house model based on the mobile home network. Chapter 4, the concluding chapter, mentions the appropriateness and expected effect of the elicited model and the future direction of study. 


\section{Theoretical Investigation}

All printed material, including text, illustrations, and charts, must be kept within the parameters of the $815 / 16$-inch (53.75 picas) column length and 5 15/16-inch (36 picas) column width. Please do not write or print outside of the column parameters. Margins are $15 / 16$ of an inch on the sides ( 8 picas), 7/8 of an inch on the top (5.5 picas), and 1 $3 / 16$ of an inch on the bottom (7 picas).

\subsection{Environment-friendly Zero-House}

The Zero House is the structure in which the sum of annual energy budget equals zero by enhancing the use of passive design use and the efficiency of machinery and equipment, greatly reducing the amount of annual energy consumption and using the self-produced renewable energy for the rest of consumption. As it rises to the higher grade, the percentage of energy use reduces but the percentage of new renentable energy becomes high. Accordingly, the Zero House should be self-sufficientin necessary energy through new renewable energy without fossil fuel and external powersupply. The Code for Sustainable Homes sets a single national standard within which the home-building industry can design and construct homes to higher environmental standards. Performance is measured across 9 key sustainable design categories, including energy/CO26 water consumption, materials, ecology, pollution and waste.

2.1.1.The Definition of Zero House: The Zero House is the structure in which the sum of annual energy budget equals zero by enhancing the use of passive design use and the efficiency of machinery and equipment, greatly reducing the amount of annual energy consumption and using the setf-produced renewable energy for the rest of consumption.

Figure 1 shows the conceptual diagram of CHS(Code for Sustainable Home), the English environment-friendly certification system.

As it rises to the higher grade, the percentage of energy use reduces but the percentage of new renewable energy becomes high. Accordingly, the Zero House should be self-sufficient in necessary energy through new renewable energy without fossil fuel and external power supply.

The Code for Sustainable Homes sets a single national standard within which the homebuilding industry can design and construct homes to higher environmental standards. Performance is measured across 9 key sustainable design categories, including energy/CO2, water consumption, materials, ecology, pollution and waste.

2.1.2. Fumctions of Zero-House: The Zero House is the structure in which the sum of annual energy budget equals

- Zero House generates its own electrical power.

- High-efficiency solar panels produce power and store it in an onboard bank of batteries. Fully charged, zeroHouse can operate continuously for up to one week with no sunlight at all.

- Zero House collects its own water.

- A rainwater collection plane gathers and diverts water into an elevated 2700 gallon cistern. All plumbing fixtures are gravity-fed, eliminating the need for power-consuming pumps.

- Zero House processes its own waste products. 
- All organic waste is processed in a digester unit located beneath the house. It converts the waste into clean, dry compost that needs to be removed only twice a year.

- Zero House is completely automatic.

All functions of the house are monitored by an array of sensors and regulated by a "house brain" that can be controlled through any laptop computer. zeroHouse is fully customizable for personal usage patterns, from the weekend getaway to extended-stay living

2.1.3. Main Technologies: The Zero House is the structure in which the sum of annual energy budget equals.

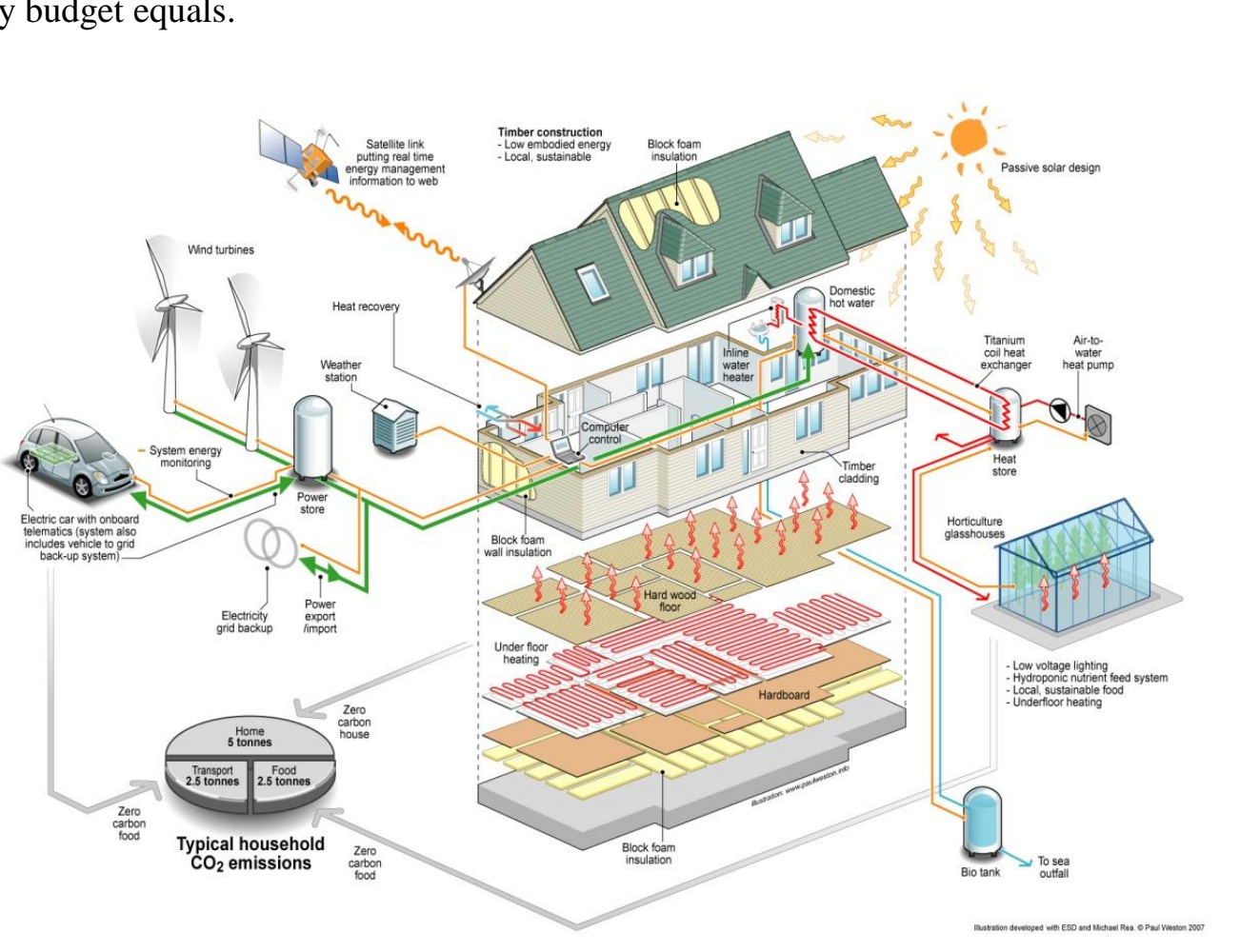

8

Figure 1. Zero carbon house schematic

- Passive Design: It responds to local climate and site conditions to maximize building users' comfort and health while minimizing energy use. It achieves this by using free, renewable sources of energy such as sun and wind to provide household heating, cooling, ventilation and lighting thereby reducing or removing the need for mechanical heating or cooling. Using passive design can reduce temperature fluctuations, improve indoor air quality and make a home drier and more enjoyable to live in. It can also reduce energy use and environmental impacts such as greenhouse gas emissions.

\section{- Active Control System/ Renewable Energy}

\subsection{Home Network}

The home network is the system to interconnect and control communications and home appliance within the home into one communications network in the ubiquitous residential environment based on the high-speed Internet. The home services of combined 
communications and broadcasting are provided for the home, such as WPAN technologycentered home automation and interactive smart TV and the like in the early form of providing simple home automation and home appliance control service. The typical wire home network technology may include Ethernet, HomePNA, PLC(Power Line Carrier), IEE 1394, USB, DVI, HDMI and so on.

\subsection{Mobile Home Network}

The mobile home network is the system that can remotely control all sorts of home appliances within the home through the network. It is the system through which at home or in the external environment, the user can control all sorts of digital equipment within the home through the smart phone. For example, its user can turn on or off gas or electronic products with the smart phone, check the outsider's invasion into the home through application and use and control distance education, healthcare, information appliances and sa on with the mobile system by connecting diverse IT appliances.

\section{Zero-House Modeling Based on Mobile Home Network}

\subsection{GT(Green IT)}

The actual configuration system is designed according to the role played by each social stratum in order to save energy. The general environmental sensor of temperature and moisture, RFID for object check, RF communication instrument for location recognition, the sensor for occupant detection, WHM(Watt Hour Meter) for the remote measurement of the amount of electricity used are installed in the mobile environment.

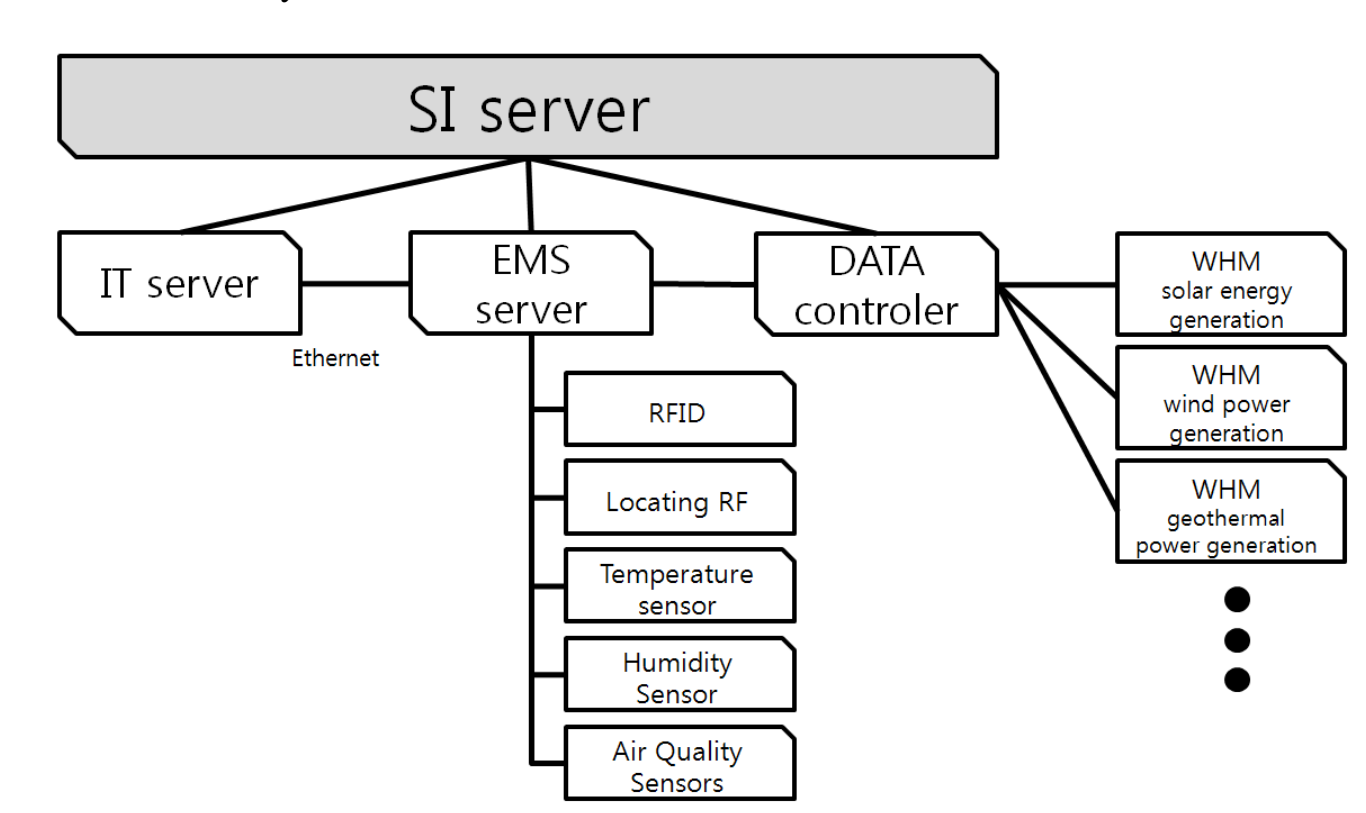

Figure 2. Mobile Space Organization System

- Construction of the network by ethernet network for data transmission, access point for Wi-Fi communications and UTP wire.

- Consistent system management through system integration(SI) and real-time server management through SI connection by the mobile appliance from the outside. 


\subsection{MEMS: Mobile Energy Management System}

The function of analyzing information on energy use feedback and data on energy use with the mobile appliance and handling total energy management.

New renewable energy: Provide real-time energy information on new renewable production such as sunlight generation, wind power generation, etc., and the energy consumption of the whole building.

Energy feedback: provide diverse statistical data such as consumed standby power, current amount of electricity used, consumption by hour, daily use time/monthly use time, maximum amount of electricity used, minimum amount of electricity used, monthly amount of electricity used, and the like.
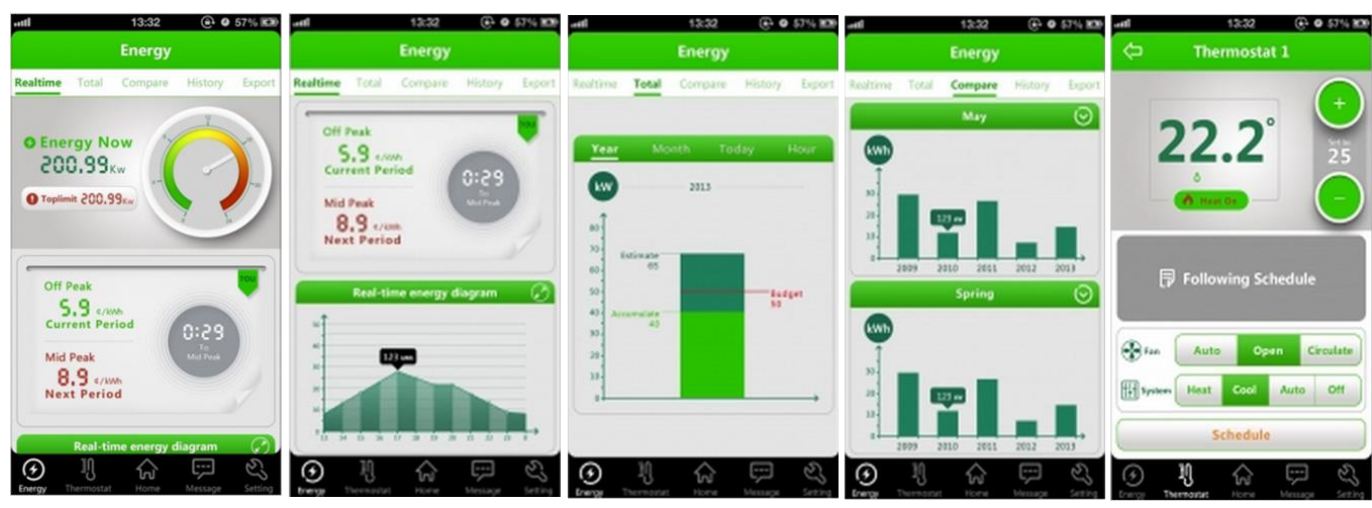

Figure 3. Mobile Intelligent Energy Management Application of Owon Company

Mobile Intelligent Energy Management Controller: LCD touch-screen module that allows users to input and control the function, besides displaying all the power usage under different categories such as lightmg, air-conditioning systems and many more. Besides, it enables a full system contro such as security surveillance, home automation and many more through multiple sensor installed such as thermostat, motion detectors which could be very useful as a centralized control system in digital home. All these can be communicated through ZigBee wireless protocol intelligently without consuming excessive energy and hardwires running across the living room.

\subsection{Mobile Súlart Home Control System}

In the smart home system, all sorts of systems are controlled through the mobile appliance.

Spart Home Surveillance System

- Smart Home Alarm System

- Smart Home Lighting Control

- Smart Home Entertainment System

- Smart Home Information Centre

- Smart Home Software Portal 


\section{Conclusion}

There may be a difference in consumed energy and emitted carbon dioxide in the structure according to the statistical standard of each country, which is known to account for 30 40\%. Countries in the world as well as Korea are continuing to study the structure of low energy consumption type which enables the building to be operated with a small amount of energy in order to reduce greenhouse gas emission. Therefore, this study conducted the eco-friendly zero-house modeling Based on mobile home network) advanced from the structure of low energy consumption type. It was designed to be self-sufficient in energy by self-producing energy through new renewable energy, applying all sorts of Zero House technology, minimizing the use of energy used in the building, and continuing to monitor and control energy through the mobile appliance. The problem of the global environment should be resolved by reducing the use of energy and reducing greenhouse gas emission through the reduction of carbon dioxide. For this purpose, it is necessary to make a continual study of the fields linked such as greenhouse gas abatement technology, energy-saving technology, new renewable energy technology and the like based on this modeling in the future.

\section{References}

[1] Y. S. Kim, "Design and Implementation of Real-time Control Systen using Embedded User Device for Intelligent Home Network", Kyungnam graduate school, (2009).

[2] B. R. Lee, S. K. Choi and Y. H. Cho, "ApStudy on Moden for Home Network High- Speed Power Line Communication System in Home Networl", The Korea Contents Society, vol. 5, no. 5, (2005), pp. 65-77.

[3] H. J. Choi and S. J. Moon, "Ubiquitous Home Network Based on Mobile Platform", The Korean Institute of Communications and Information Sciences, no.11, (2010), pp. 565-566.

[4] http://www.owon-smart.com/uploadfile/upload/Owon-smart\%20brochure.pdf.

[5] http/http://www.planningportal.gov.uk/upløads/code_for_sust_homes.pdf.

[6] http://zerohouse.net/wordpress/how-it-works.

[7] http://www.mydigitallife info/control-4-ec-100-an-intellingent-energy-management-home-control-system-indigital-home/.

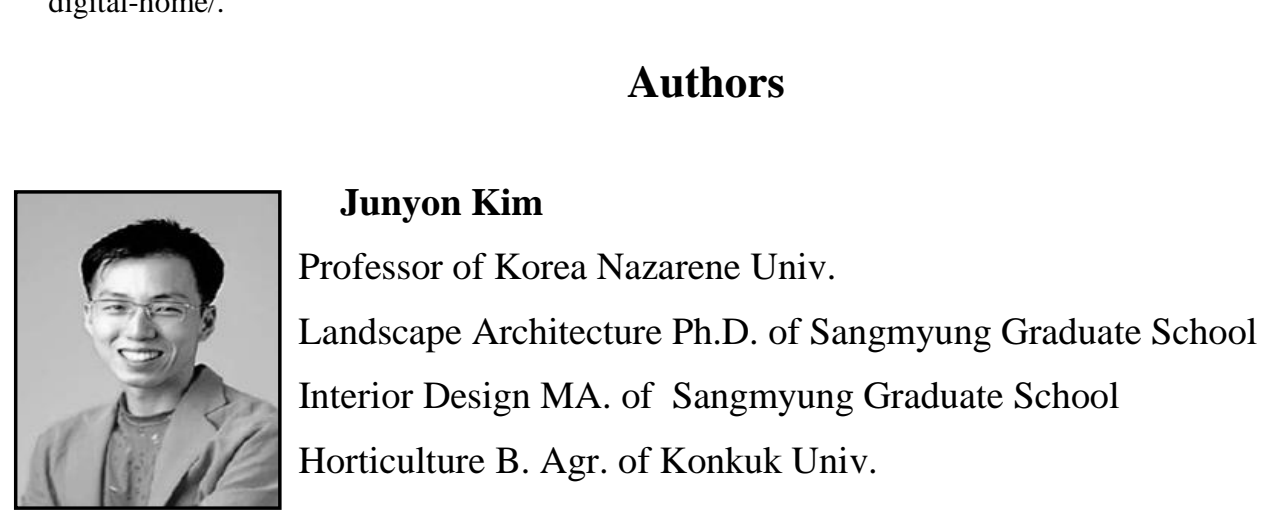

